\title{
Development and Validation of Spectrophotometric Methods for the Determination of Rasagiline in Pharmaceutical Preparations
}

\author{
Serife Evrim Kepekci Tekkeli, ${ }^{1}$ Armağan Önal, ${ }^{2}$ and Fatemeh Bahadori ${ }^{3}$ \\ ${ }^{1}$ Bezmialem Vakif University, Faculty of Pharmacy, Department of Analytical Chemistry, Fatih, 34093 Istanbul, Turkey \\ ${ }^{2}$ Istanbul University, Faculty of Pharmacy, Department of Analytical Chemistry, Beyazit, 34116 Istanbul, Turkey \\ ${ }^{3}$ Bezmialem Vakif University, Faculty of Pharmacy, Department of Pharmaceutical Biotechnology, Fatih, 34093 Istanbul, Turkey
}

Correspondence should be addressed to Serife Evrim Kepekci Tekkeli; evrimkepekci@yahoo.com

Received 29 May 2013; Revised 16 July 2013; Accepted 18 July 2013

Academic Editor: Naoki Asakawa

Copyright (C) 2013 Serife Evrim Kepekci Tekkeli et al. This is an open access article distributed under the Creative Commons Attribution License, which permits unrestricted use, distribution, and reproduction in any medium, provided the original work is properly cited.

\begin{abstract}
This study presents three simple, rapid, and accurate spectrophotometric methods for the determination of Rasagiline (RSG) in pharmaceutical preparations. The determination procedures depend on the reaction of RSG with chloranilic acid for method A, tetrachloro-1,4-benzoquinone for method B, and 7,7,8,8-tetracyanoquinodimethane for method C. The colored products were quantitated spectrophotometrically at 524,535, and $843 \mathrm{~nm}$ for methods A, B, and C, respectively. Different variables affecting the reaction were optimized. Linearity ranges of the methods with good correlation coefficients (0.9988-0.9996) were observed as $25-$ $300 \mu \mathrm{g} \mathrm{mL} L^{-1}, 25-350 \mu \mathrm{g} \mathrm{mL}^{-1}$, and $50-500 \mu \mathrm{g} \mathrm{mL}^{-1}$ for methods $\mathrm{A}, \mathrm{B}$, and $\mathrm{C}$, respectively. The formation of products takes place through different mechanisms. The sites of interaction were confirmed by elemental analysis using IR and ${ }^{1} \mathrm{H}-\mathrm{NMR}$ spectroscopy. The validation of the methods was carried out in terms of specificity, linearity, accuracy, precision, robustness, limit of detection, and limit of quantitation. No interference was observed from concomitants usually present in dosage forms. The methods were applied successfully to the determination of RSG in pharmaceutical preparations.
\end{abstract}

\section{Introduction}

In Parkinson's disease, one of the most prominent pathologies is the progressive degeneration of melanin-containing neurons in the substantia nigra pars com-pacta, resulting in the depletion of nigrostriatal dopamine [1]. Rasagiline (RSG) is a potent selective irreversible inhibitor of monoamine oxidase type B (2) and has been used for the treatment of idiopathic Parkinson's disease [2].

The reported analytical methods for determination of RSG include high-performance liquid chromatography (HPLC) [3-6], spectrophotometry [7, 8], and gas chromatography combined with mass spectrometry (GC-MS) [9]. No spectrophotometric method using $\pi$-acceptors was reported in the literature. $\pi$-acceptors such as chloranilic acid (CA), tetrachloro-1,4-benzoquinone (p-chloranil), and 7,7,8,8-tetracyanoquinodimethane (TCNQ) are known to yield charge transfer (CT) complexes and radical anions with a variety of electron donors [10-15]. The spectrophotometric methods, based on these interactions, are usually simple and applicable for drug substances. Therefore, the aim of the present study was directed to investigate simple, rapid, sensitive, and cost-effective spectrophotometric methods based on the reactions using $\pi$-acceptors. The developed analytical procedures depend on the reaction of RSG with $\mathrm{CA}$ is expressed as method $\mathrm{A}$, with $\mathrm{p}$-chloranil is expressed as method B, and with TCNQ is signified as method C. The structure of the final products in the solid phase has been characterized using ${ }^{1} \mathrm{H}-\mathrm{NMR}$ and FTIR spectra.

\section{Experimental}

2.1. Instrumentation. Spectrophotometric measurements were carried out by using a Hitachi spectrometer Model U-2900 equipped with Xenon lamp and 1-cm quartz cells. 
The FTIR spectra of the reactants and the resulting products were recorded using $\mathrm{KBr}$ disc on Thermo Nicolet 6700 FTIR spectrometer. ${ }^{1} \mathrm{H}$-NMR spectra of the products, donors, and acceptors were recorded in DMSO using Varian Mercury $\left({ }^{1} \mathrm{H}: 400 \mathrm{mHz}\right) 400 \mathrm{NMR}$ Spectrometer.

2.2. Chemicals and Solutions. RSG mesylate was kindly supplied by Abdi Ibrahim Pharmaceuticals (Istanbul, Turkey) and its pharmaceutical preparation (Rasalas) containing $1 \mathrm{mg}$ of RSG per film tablet was obtained from local drug store. All chemicals and reagents were of analytical grade.

Stock solution of RSG $\left(1 \mathrm{mg} \mathrm{mL}^{-1}\right)$ was prepared by dissolving RSG mesylate equivalent to $10 \mathrm{mg}$ RSG in $10 \mathrm{~mL}$ water.

TCNQ (Fluka-Neu-Ulm, Germany), CA, and p-chloranil Merck (Darmstadt, Germany) were freshly prepared as $0.2 \%$, $0.1 \%(\mathrm{w} / \mathrm{v})$ solutions in acetonitrile and $1 \%(\mathrm{w} / \mathrm{v})$ solution in acetone, respectively; the solutions were stable for 1 week at $4^{\circ} \mathrm{C}$.

2.3. General Procedure. Into $5 \mathrm{~mL}$ calibrated flasks $0.125-$ $1.50 \mathrm{~mL}, 0.125-1.75 \mathrm{~mL}$, and $0.25-2.5 \mathrm{~mL}$ aliquots of RSG stock solution were placed for methods $\mathrm{A}, \mathrm{B}$, and $\mathrm{C}$, respectively. The volume was brought to $1.50 \mathrm{~mL}$ (for method A), $1.75 \mathrm{~mL}$ (for method B), and $2.5 \mathrm{~mL}$ (for method C) with acetonitrile. Then $0.5 \mathrm{~mL}$ of chloranilic acid, $0.5 \mathrm{~mL}$ of pchloranil, and $1.0 \mathrm{~mL}$ of TCNQ were added. The reaction mixture was allowed to stand for $5 \mathrm{~min}$ at room temperature for methods $\mathrm{A}$ and $\mathrm{B}$ and was heated for $5 \mathrm{~min}$ at $80^{\circ} \mathrm{C}$ for method C. After cooling and diluting each mixture to $5 \mathrm{~mL}$ with acetonitrile the absorbances were measured at 524, 535, and $843 \mathrm{~nm}$ for methods $\mathrm{A}, \mathrm{B}$, and C, respectively, against a reagent blank prepared in the same manner. The calibration graphs for each method were prepared by plotting absorbance values versus concentration of RSG.

2.4. Preparation of Calibration Curves. Calibration curves for each method were prepared by the analysis of stock solution of RSG $\left(1 \mathrm{mg} \mathrm{mL}^{-1}\right)$ with various dilutions. The samples were then submitted to the processes described in General Procedure. Calibration curves were obtained by linear leastsquares regression analysis plotting of absorbance values versus the concentrations. For each method the calibration curve equation is $A=a C+b$, where $C$ is the concentrations in $\mu \mathrm{g} \mathrm{mL}^{-1}$ and $A$ is the absorbance values.

2.5. Assay Procedure for Tablets. Ten film tablets were transferred to a $250 \mathrm{~mL}$ volumetric flask. About $125 \mathrm{~mL}$ of acetonitrile was added and then extraction was performed mechanically for 20 minutes and sonicated for 20 more minutes. The volume was brought to $250 \mathrm{~mL}$ with acetonitrile and the final solution was filtered. Aliquots of filtrate were diluted further with acetonitrile and then proceeded as described under preparation of the calibration curve. The nominal content of the tablets was calculated using either the calibration graph or the corresponding regression equation.
2.6. Synthesis of the Solid CT Complexes. The reaction products were synthesized by adding a saturated solution of RSG $(256.9 \mathrm{mg}, 1.5 \mathrm{mmol})$ in water to each reagent solution (to a saturated solution of CA (313.5.mg, $1.5 \mathrm{mmol}$ ), pchloranil (328 mg, $1.3 \mathrm{mmol}$ ), and TCNQ (204 mg, $1 \mathrm{mmol}$ )). The mixtures were stirred for about $30 \mathrm{~min}$ and then filtered to avoid the contamination with any unreacted species. The solutions were then left nearly $2 \mathrm{~h}$ to obtain the solid reaction products, filtered, and washed several times with acetonitrile in order to remove the residual reagents and drug substance. It was observed that the reaction products have low solubility in acetonitrile.

\section{Results and Discussion}

It has been observed that interaction of charge transfer complexes and RSG goes through different reaction mechanisms in each case. In method A, the reaction between RSG and CA causes a charge transfer complex formation; in method B, RSG and p-chloranil interaction brings a new chemical bond; in method C, in reaction between RSG and TCNQ the latter agent transforms into its radical anion form $\left(\mathrm{TCNQ}^{-}{ }^{-}\right)$. The maximum absorbance of described products was observed at 524,535 , and $843 \mathrm{~nm}$, respectively (Figure 1 ). The reactions between RSG and reactants were given in Figure 2.

The influence of some variables on the reactions has been tested as follows.

\subsection{Optimization of the Methods}

3.1.1. Choice of Solvent. Different solvents including acetonitrile, chloroform, methanol, acetone, ethanol, 1,4-dioxane, and methylene chloride were investigated in order to select the suitable solvent. Experiments indicate that acetonitrile is proved to be the most suitable diluting solvent because it affords an excellent solvating power for CA, p-chloranil, and TCNQ reagents and gives the highest absorbance value. Specially, acetonitrile, being a polar solvent, facilitates the complete transfer of charge from donor to acceptor with the formation of radical anion as the predominant chromogen. Although the formation of TCNQ ${ }^{-}$radical was possible in methanol and ethanol, the color intensity was lower within those solvents comparing with that of acetonitrile.

3.1.2. Reagent Concentration. When various concentrations of the reactants were added to a fixed concentration of RSG, $0.5 \mathrm{~mL}$ of $0.1 \% \mathrm{CA}, 0.5 \mathrm{~mL}$ of $1 \% \mathrm{p}$-chloranil, and $1.0 \mathrm{~mL}$ of $0.2 \%$ TCNQ solution $0.2 \%[\mathrm{w} / \mathrm{v}]$ were found to be sufficient for the production of maximum and reproducible color intensity (Figure 3).

3.1.3. Reaction Time. The intensity of absorbances of the colored products at different time intervals and temperatures for all methods was investigated. Complete color development was attained after 5 minutes at $80^{\circ} \mathrm{C}$ for method $\mathrm{A}$, whereas for methods B and C complete color development was obtained at room temperature in the same time period (Figure 4). The colors remained stable for $24 \mathrm{~h}$ for all reagents. 


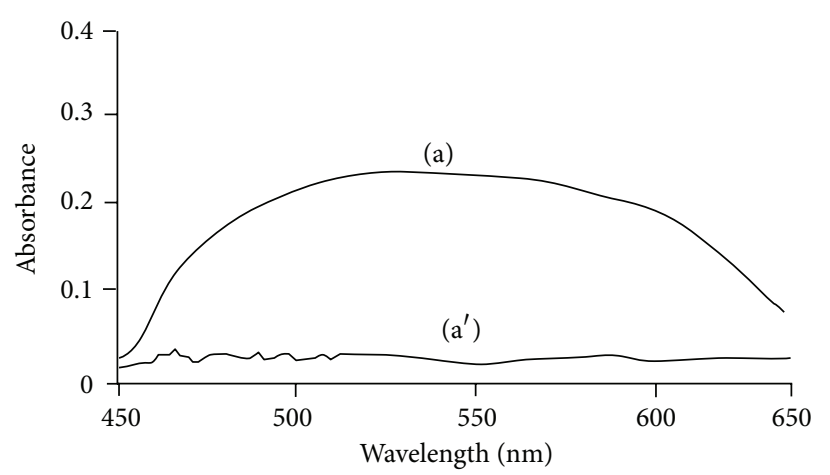

(A)

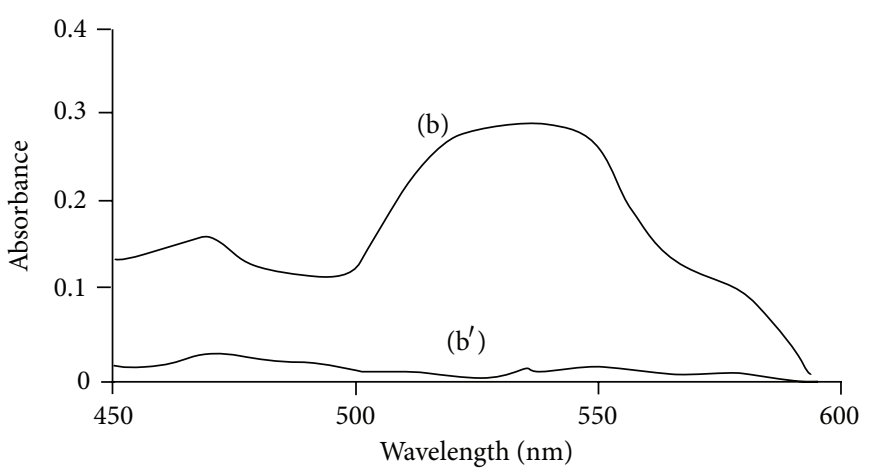

(B)

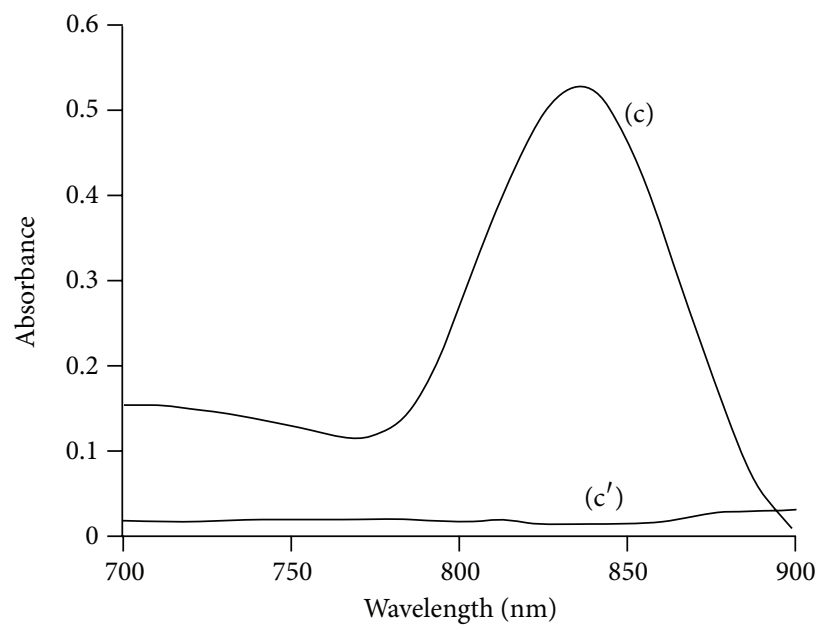

(C)

FIGURE 1: (A): (a) Absorption spectrum of $35 \mu \mathrm{g} \mathrm{mL} \mathrm{L}^{-1}$ of the product occurred in method A against reagent blank and ( $\left.\mathrm{a}^{\prime}\right)$ absorption spectrum of the reagent blank of method A. (B): (b) Absorption spectrum of $30 \mu \mathrm{g} \mathrm{mL}^{-1}$ of the product occurred in method B against reagent blank and $\left(b^{\prime}\right)$ absorption spectrum of the reagent blank of method B. (C): (c) Absorption spectrum of $55 \mu \mathrm{g} \mathrm{mL} \mathrm{L}^{-1}$ of the product occurred in method $\mathrm{C}$ against reagent blank and $\left(\mathrm{c}^{\prime}\right)$ absorption spectrum of the reagent blank of method $\mathrm{C}$.

3.1.4. Stoichiometry of the Reaction. To determine the reaction stoichiometry Job's method of continuous variation was used [16]. According to this procedure, for each method, a series of reaction mixtures were prepared with different mole ratios of reagent to RSG from 0 to 2, while keeping the total number of moles of reactants constant. The absorbances of the reaction products were measured and graphed versus the mole ratios. For each method the graph is a curve with two regions: at the first region the absorbance increases directly proportional to mole ratio and the slope of this part of the curve is positive; at the second region of the curve the increase in mole ratio causes decrease in absorbance by observing a negative slope. The point of intersection of the two linear extrapolations corresponds to the mole ratio of reagent to RSG indicating the optimum mole ratio.

For all methods the stoichiometry of the reactions was found as $1: 1$ ratio (reagent/RSG).

3.2. Method Validation. The developed analytical methods were validated in accordance with the ICH guideline Q2
[R1] [17]. Under the described experimental conditions, calibration graphs were constructed for all of the methods and Table 1 summarizes the values for Beer's law limits, regression equation, correlation coefficients, molar absorptivity, Sandel's sensitivity, limit of detection [LOD] and limit of quantification [LOQ], for each method. As can be seen from Table 1, linear relationship was found between the absorbance at $\lambda_{\max }$ and the concentration of the drug in the ranges 20-250 $\mu \mathrm{g} \mathrm{mL}^{-1}, 25-400 \mu \mathrm{g} \mathrm{mL}^{-1}$, and $20-500 \mu \mathrm{g} \mathrm{mL}^{-1}$ for methods A, B, and C, respectively. Method A was the most sensitive one, with the highest $\varepsilon$ value. The LOD and LOQ were determined using the formula: $\mathrm{LOD}$ or $\mathrm{LOQ}=\kappa \mathrm{SD}_{a} / b$, where $\kappa=3$ for LOD and 10 for LOQ, SDa is the standard deviation of the intercept, and $b$ is the slope. The inter- and intraday precisions were examined by analysis of RSG with the concentrations of 25,100 , and $200 \mu \mathrm{g} \mathrm{mL} \mathrm{mL}^{-1}$ for method $\mathrm{A}, 25,100$, and $250 \mu \mathrm{g} \mathrm{mL}^{-1}$ for method B, and 50, 200, and $400 \mu \mathrm{g} \mathrm{mL}^{-1}$ for method $\mathrm{C}$ [each $n=5$ ] for seven consecutive days. The RSD\% values for intraday precision and inter-day precision were found for all developed methods, which indicate good precision. The obtained results are 


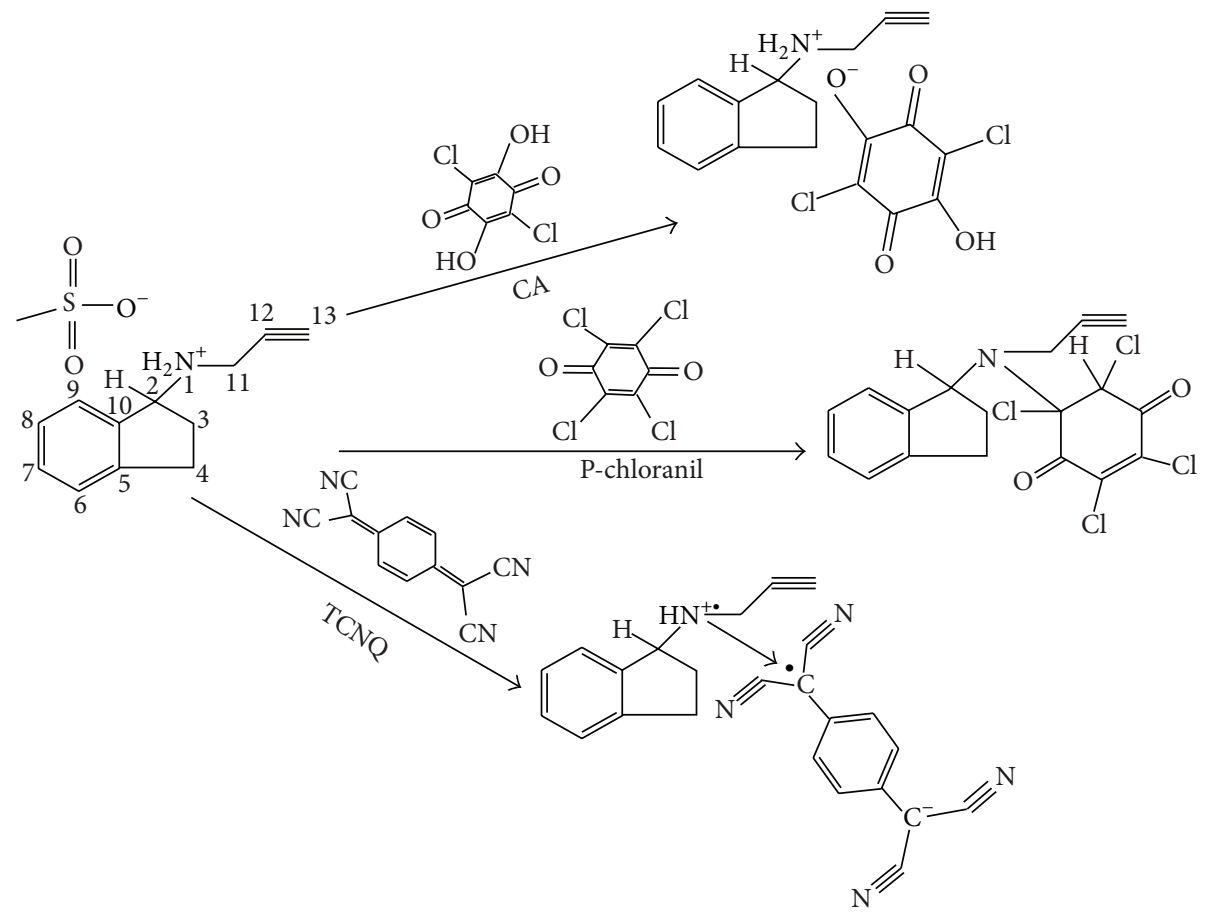

FIGURE 2: The reaction pathways between RSG and the reactants.

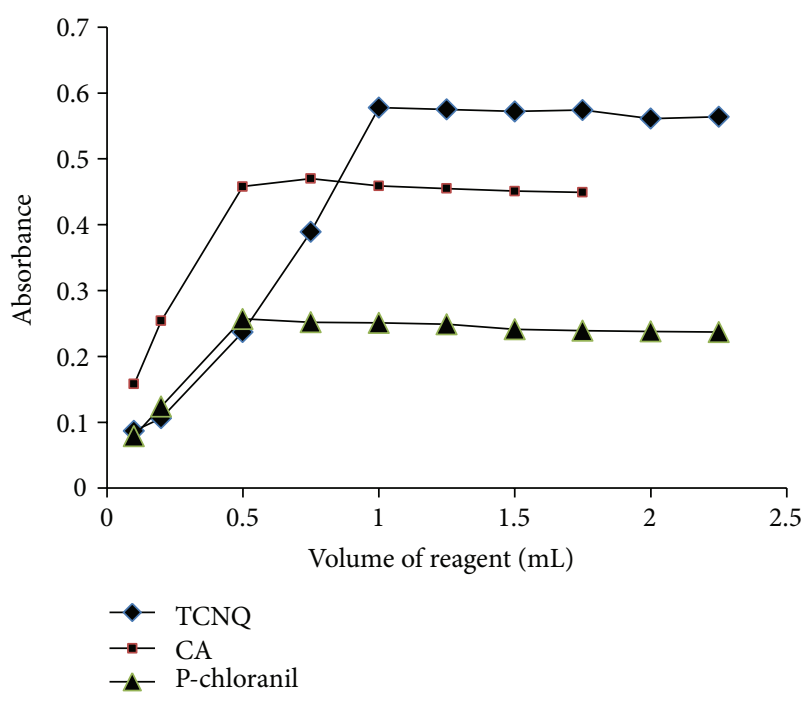

FIGURE 3: Effect of volumes of the reagents used for method A (CA $[0.1 \%, \mathrm{w} / \mathrm{v}]), \mathrm{B}(\mathrm{p}$-chloranil $[1 \%, \mathrm{w} / \mathrm{v}])$, and C (TCNQ [0.2\%, w/v]) with the drug substance concentration is $150 \mu \mathrm{g} \mathrm{mL}^{-1}, 75 \mu \mathrm{g} \mathrm{mL}{ }^{-1}$, $350 \mu \mathrm{g} \mathrm{mL}^{-1}$ for methods $\mathrm{A}, \mathrm{B}$, and $\mathrm{C}$, respectively.

summarized in Table 1 which summarizes the analytical parameters.

To check the accuracy of the proposed methods, standard addition technique was applied. Different amounts of pure sample solution were added to standard drug solutions in three different concentrations and were assayed. The percent

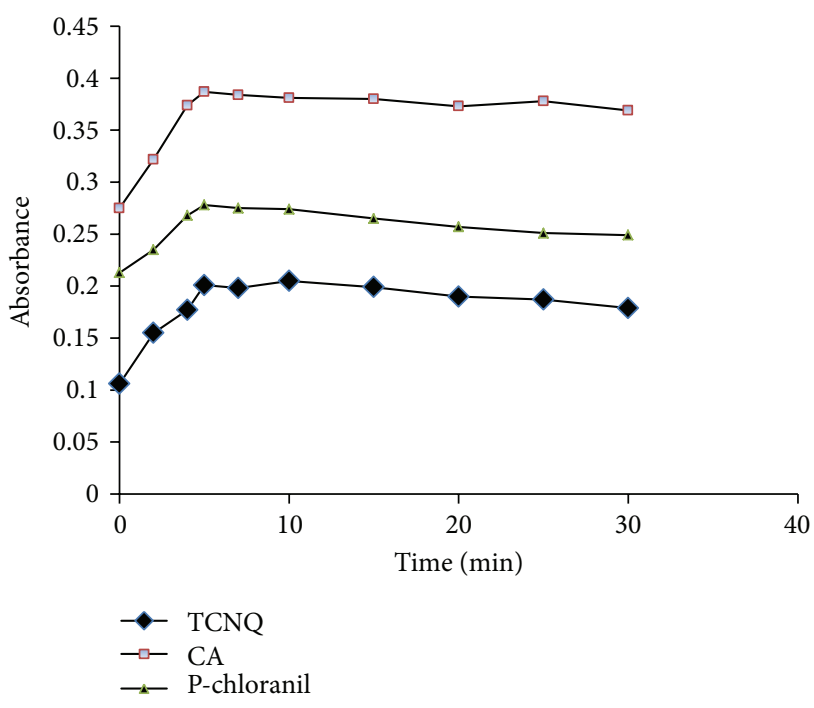

FIGURE 4: The effect of time on the reaction for methods A, B [ $\downarrow$, at room temperature], and $\mathrm{C}\left[\mathbf{\square}\right.$, at $\left.80^{\circ} \mathrm{C}\right]$ with the drug substance concentration is $75 \mu \mathrm{g} \mathrm{mL}^{-1}, 100 \mu \mathrm{g} \mathrm{mL}^{-1}$, and $75 \mu \mathrm{g} \mathrm{mL}^{-1}$, respectively.

recoveries of the added sample solutions to the assay samples were calculated from

$$
\text { Recovery\% }=\left[\frac{\left[C_{t}-C_{u}\right]}{C_{a}}\right] \times 100,
$$

where $C_{t}$ is the total concentration of the analyte found, $C_{u}$ is the concentration of the analyte present in the formulation, 
TABLE 1: Results of analytical parameters for proposed methods.

\begin{tabular}{|c|c|c|c|}
\hline & Method A & Method B & Method C \\
\hline Linearity range $^{\mathrm{a}}\left[\mu \mathrm{g} \mathrm{mL}^{-1}\right]$ & $25-300$ & $25-350$ & $50-500$ \\
\hline Molar absorptivity $\left[1 \mathrm{~mol}^{-1} \mathrm{~cm}^{-1}\right]$ & $3.46 \times 10^{3}$ & $2.31 \times 10^{3}$ & $1.6 \times 10^{3}$ \\
\hline Sandel's sensitivity [ $\mu \mathrm{g} \mathrm{cm}^{-2}$ per 0.001 absorbance unit] & $5.56 \times 10^{-2}$ & $7.41 \times 10^{-2}$ & $1.02 \times 10^{-1}$ \\
\hline \multicolumn{4}{|l|}{ Precision } \\
\hline Intraday ${ }^{\mathrm{b}}, \mathrm{RSD} \%$ & 0.75 & 0.82 & 0.56 \\
\hline Interdayc ${ }^{\mathrm{c}}, \mathrm{RSD} \%$ & 1.02 & 1.15 & 1.27 \\
\hline \multicolumn{4}{|l|}{ Regression equation $^{\mathrm{d}}$} \\
\hline Slope \pm SD & $0.0028 \pm 0.00006$ & $0.0024 \pm 0.00002$ & $0.0015 \pm 0.00003$ \\
\hline Intercept $\pm S D$ & $0.0777 \pm 0.00011$ & $0.0263 \pm 0.00024$ & $0.0381 \pm 0.00005$ \\
\hline Correlation coefficient, $r$ & 0.9996 & 0.9996 & 0.9983 \\
\hline $\mathrm{LOD}\left[\mu \mathrm{g} \mathrm{mL}^{-1}\right]$ & 0.122 & 0.279 & 0.583 \\
\hline $\mathrm{LOQ}\left[\mu \mathrm{g} \mathrm{mL}^{-1}\right]$ & 0.407 & 0.932 & 1.94 \\
\hline
\end{tabular}

${ }^{a}$ Average of six determinations.

${ }^{\mathrm{b}} n=5$ corresponding to replicate analysis for each level.

${ }^{\mathrm{c}}$ Results of five different days.

${ }^{\mathrm{d}} A=a+b C\left[C\right.$ is the concentration of drug in $\mu \mathrm{g} \mathrm{mL}^{-1}$ and $A$ is the absorbance at $\left.\lambda_{\max }\right]$.

TABLE 2: Results of recovery studies by standard addition method.

\begin{tabular}{|c|c|c|c|c|c|}
\hline Method & $\begin{array}{l}\text { Amount taken } \\
{\left[\mu \mathrm{g} \mathrm{mL}^{-1}\right]^{\mathrm{a}}}\end{array}$ & $\begin{array}{l}\text { Amount added } \\
{\left[\mu \mathrm{g} \mathrm{mL}^{-1}\right]}\end{array}$ & $\begin{array}{c}\text { Total amount found } \\
{\left[\mu \mathrm{g} \mathrm{mL}^{-1}\right]} \\
{\left[\text { Mean } \pm \text { S.D. }{ }^{\mathrm{c}}\right]}\end{array}$ & Recovery [\%] & RSD [\%] \\
\hline \multirow{3}{*}{ Method A } & \multirow{3}{*}{100} & 25 & $125.247 \pm 1.14$ & 100.99 & 1.23 \\
\hline & & 100 & $200.187 \pm 1.58$ & 100.19 & 0.93 \\
\hline & & 200 & $300.132 \pm 2.58$ & 100.07 & 0.96 \\
\hline \multirow{3}{*}{ Method B } & \multirow{3}{*}{100} & 25 & $125.14 \pm 1.34$ & 100.56 & 1.49 \\
\hline & & 100 & $200.36 \pm 1.87$ & 100.36 & 1.02 \\
\hline & & 250 & $351.49 \pm 2.56$ & 100.60 & 0.84 \\
\hline \multirow{3}{*}{ Method C } & \multirow{3}{*}{100} & 50 & $150.24 \pm 1.14$ & 100.48 & 0.79 \\
\hline & & 200 & $303.01 \pm 1.58$ & 101.51 & 0.76 \\
\hline & & 400 & $504.36 \pm 3.87$ & 101.09 & 0.81 \\
\hline
\end{tabular}

${ }^{a}$ Rasalas tablet $[1 \mathrm{mg}]$.

${ }^{\mathrm{b}}$ Five independent analyses.

${ }^{\mathrm{c}}$ Standard deviation.

and $C_{a}$ is the concentration of the pure analyte added to the formulation. The results of analysis of the commercial dosage forms and the recovery study were shown in Table 2 . The average percent recoveries obtained were $100.41 \%, 100.51 \%$ and $101.03 \%$ for methods A, B, and C, respectively, indicating good accuracy of the methods.

The applicability of the proposed method was tested by the determination of RSG in tablets. The results are satisfactorily accurate and precise as indicated by the excellent $\%$ recovery and $\mathrm{SD}<2$ (Table 3 ). Experiments showed that there was no interference from the additives and excipients, for example, lactose, glucose, fructose, magnesium stearate, and starch.

\subsection{Characterization of the Reaction Products}

3.3.1. IR Spectra of RSG with Reagents. The IR spectra of RSG showed the expected $-\mathrm{NH},-\mathrm{NH}_{2}{ }^{+}$, terminal $-\mathrm{C} \equiv \mathrm{C}-$, and
TABLE 3: Analysis of RSG in tablet containing $50 \mathrm{mg}$ of the drug $[n=$ $5]$.

\begin{tabular}{lccc}
\hline & $\begin{array}{c}\text { Method A } \\
{\left[\text { Mean } \pm \text { S.D. }{ }^{c} \text { ] }\right.}\end{array}$ & $\begin{array}{c}\text { Method B } \\
{\left[\text { Mean } \pm \text { S.D. }{ }^{c}\right]}\end{array}$ & $\begin{array}{c}\text { Method C } \\
{\left[\text { Mean } \pm \text { S.D. }{ }^{c}\right]}\end{array}$ \\
\hline Mean \pm S.D & $1.016 \pm 0.0029$ & $1.007 \pm 0.046$ & $1.013 \pm 0.0027$ \\
Recovery [\%] & 101.60 & 100.65 & 101.32 \\
RSD [\%] & 0.29 & 0.46 & 0.26 \\
\hline
\end{tabular}

${ }^{\mathrm{a}}$ Rasalas tablet $[1 \mathrm{mg}]$.

${ }^{\mathrm{b}}$ Five independent analyses.

${ }^{\mathrm{c}}$ Standard deviation.

aromatic stretches at 3357, 2402, 2131, and aromatic region from 2790 to $2994 \mathrm{~cm}^{-1}$, respectively. Together with this the $\mathrm{SO}_{2} \mathrm{O}$ bending of methanesulfonic acid was observed at $1171 \mathrm{~cm}^{-1}$. The IR spectra of CA give an $-\mathrm{OH}$ peak at $3233 \mathrm{~cm}^{-1}, \mathrm{C}=\mathrm{O}$ stretch at 1665 and $1626 \mathrm{~cm}^{-1}$, and $\mathrm{C}-\mathrm{O}$ at 
$1359 \mathrm{~cm}^{-1}$ which coincides with previously reported data [18]. In the IR spectra of the reaction product of method $A$, the $-\mathrm{OH}$ peak of CA shifts to $3251 \mathrm{~cm}^{-1}$ [shielding the $-\mathrm{N}-\mathrm{H}$ stretching of RSG which seems to be shifted to $3500 \mathrm{~cm}^{-1}$ ] with a reduction in intensity and two bending peaks related to $-\mathrm{N}^{+}-\mathrm{O}^{-}$appears at 1282 and $981 \mathrm{~cm}^{-1}$ [19]. Thus, it seems that the complex of the drug molecules and CA is an ionic behavior and RSG is playing the cationic role in this complex.

The IR spectra of p-chloranil give $\mathrm{C}=\mathrm{O}$ stretch at 1688 and $1677 \mathrm{~cm}^{-1}$ and $\mathrm{C}-\mathrm{O}$ at $1315 \mathrm{~cm}^{-1}$. In the IR spectra of the reaction product of method $\mathrm{B}$, the $-\mathrm{NH}$ peak at $3420 \mathrm{~cm}^{-1}$ is being lost and a new $\mathrm{C}-\mathrm{N}$ stretch is being observed at $1103 \mathrm{~cm}^{-1}$ indicating the formation of a new $\mathrm{C}-\mathrm{N}$ bound between RSG and p-chloranil molecules.

The IR spectra of TCNQ reported a $-\mathrm{C} \equiv \mathrm{N}-$ stretch at $2223 \mathrm{~cm}^{-1}$ [11] and $\mathrm{C}=\mathrm{C}$ stretching at $1619 \mathrm{~cm}^{-1}$. Interestingly except for $-\mathrm{NH}$ stretching of RSG and $-\mathrm{C} \equiv \mathrm{N}$ - stretching of TCNQ no other significant change was observed in this IR spectrum. Fortunately, the radical anions of TCNQ versus salt form of other compounds have been studied in details [20]. According to this data occurrence of $-\mathrm{C} \equiv \mathrm{N}-$ stretching band of TCNQ in lower wave number together with a broadening of $-\mathrm{NH}$ group indicates the anionic radical behavior of TCNQ. In the spectra of the reaction product of method $\mathrm{C}$, a slight downshifting of $-\mathrm{C} \equiv \mathrm{N}-$ stretching from 2223 to $2182 \mathrm{~cm}^{-1}$, together with broadening of $\mathrm{N}-\mathrm{H}$ peak at $3395 \mathrm{~cm}^{-1}$, was observed. Together with this evidence neither the aromatic region is changed nor the $-\mathrm{NH}$ group is disappeared. All the above observations led us to the conclusion of having RSG-TCNQ in ionic radical form.

3.3.2. ${ }^{1} \mathrm{H}$-NMR Spectra of RSG with the Reagents. In the ${ }^{1} \mathrm{H}-$ NMR spectra of RSG, except the broad singlet peak of $\mathrm{NH}_{2}{ }^{+}$ at $9.50 \mathrm{ppm}$, there are two main types of peaks: aromatic and aliphatic peaks. The protons that belong to the aromatic ring appear at $7.60(1 \mathrm{H}), 7.34(2 \mathrm{H})$, and $7.28(1 \mathrm{H}) \mathrm{ppm}$ corresponding to C-6, [C-7, C-8], and C-9, respectively. A deshielded multiplet aliphatic proton at $\sigma 4.79 \mathrm{ppm}$ belongs to the proton of nitrogen neighboring C-2. Protons of C-11 $(2 \mathrm{H})$ are being overlapped with the methyl protons of methane sulfonic acid. However, it has been reported that these two

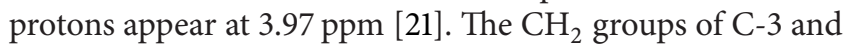
4 appear at $3.08,2.85,2.42$, and $2.19 \mathrm{ppm}$, each corresponding to one proton as multiplets. And finally the terminal methine proton is observed at $\sigma 2.33$ as a singlet (Figure 5).

We expect the complete disappearance of $\mathrm{NH}_{2}{ }^{+}$protons in case of formation of any chemical bounds between this group and any of reagents. This happens only in case of using p-chloranil in method $\mathrm{B}$, as complexation agent. In the spectra of the reaction product of method $B$, together with disappearance of the above-mentioned peak, a singlet peak corresponding to one proton is being appeared at $6.50 \mathrm{ppm}$ indicating the reduction of double bound of p-chloranil at the site of connection. Along with these, the nitrogen neighboring $\mathrm{CH}_{2}$ group shifts up field and shows up getting rid of mesylate methyl protons (Figure 6).

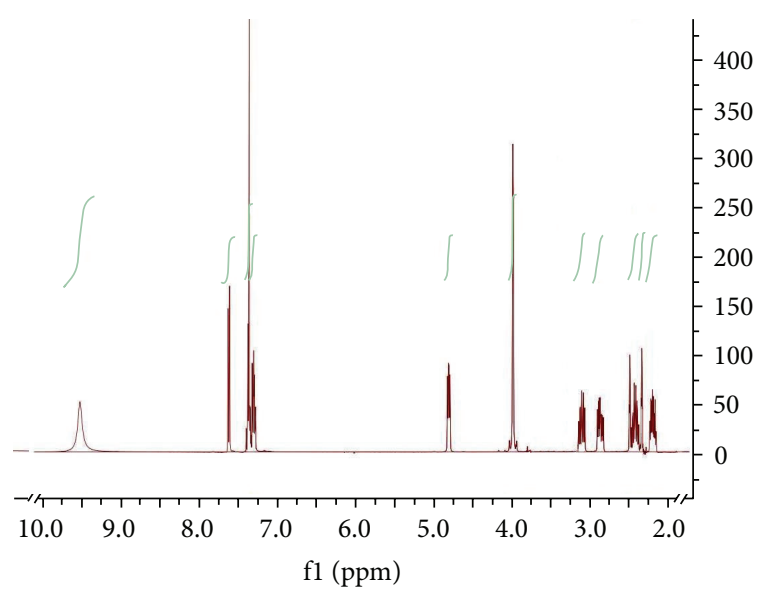

FIGURE 5: NMR spectrum of RSG mesylate.

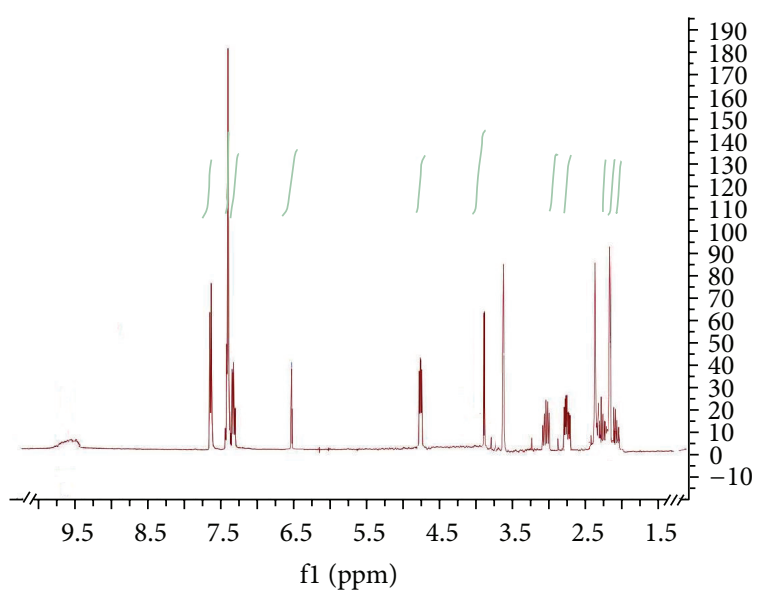

FIGURE 6: NMR spectrum of the product of method B.

In the spectra of the reaction products of methods $\mathrm{A}$ and $\mathrm{C}$, no change in $\mathrm{NH}_{2}{ }^{+}$protons was observed. Together with this there is no change in the aromatic region peaks of complexes comparing with those of RSG. It has previously been reported [22] that when there is a donor group on the aromatic ring of the drug molecule, it is possible for ion transfer agents to behave as acceptor which, consequently, causes a significant change on the aromatic ring chemical shifts of the drug molecule. Probably because of lack of this option on RSG molecule, there is no change in the above-mentioned chemical shifts of RSG-CA and TCNQ. The only remarkable change in the spectra of RSG-CA is recording the proton of $\mathrm{C}-2$ as broadened singlet instead of multiplet. Since the multiplicity of this proton is due to its coupling with protons of $\mathrm{C}-3$, it seems that there is an electron exchange between CA and RSG in which the sterical hindrance of complexation molecule inhibits the above-mentioned coupling. A change in the chemical shift of methyl group of mesylate from 3.97 to 3.69 indicates a change in position of mesylate group as well (Figure 7).

There is no change in the ${ }^{1} \mathrm{H}$-NMR spectra of the reaction product of method $\mathrm{C}$. However the anionic radical made by 


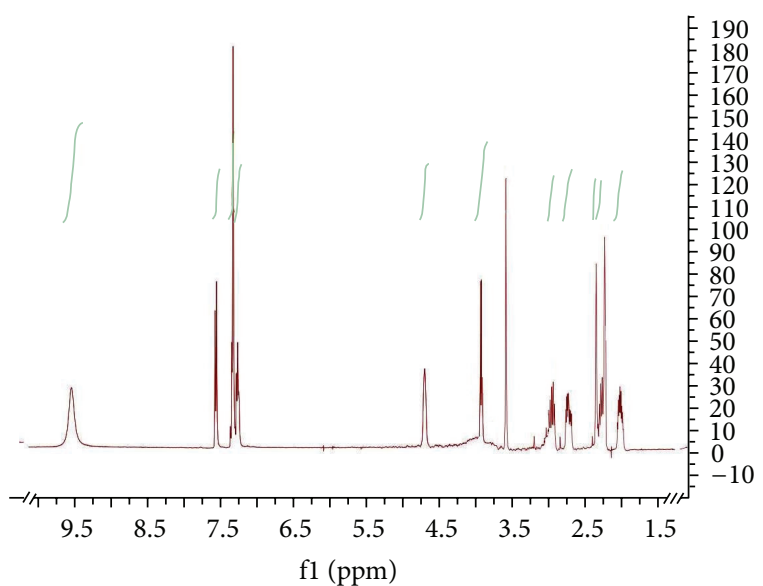

FIgURE 7: NMR spectrum of the product of method A.

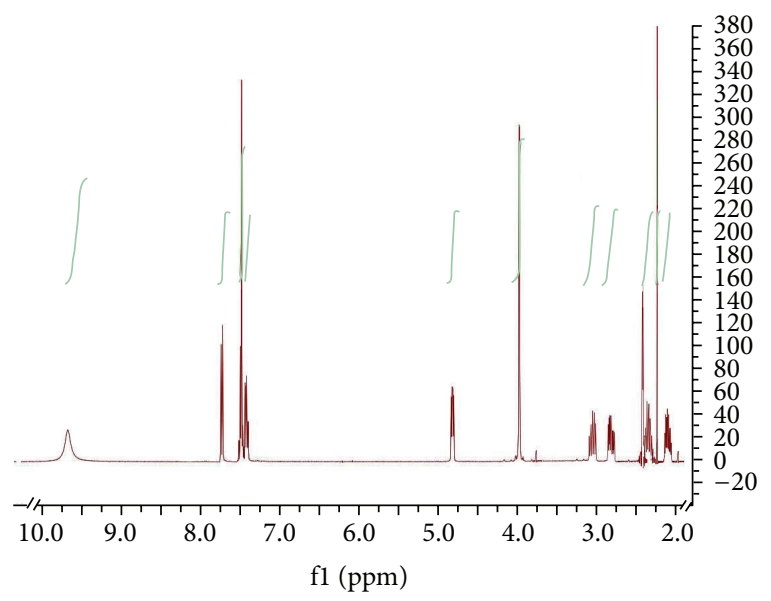

FIGURE 8: NMR spectrum of the reaction product of method C.

complexation of TCNQ and RSG is being mentioned in IR spectra part. It seems that carrying a lone electron on nitrogen atom does not affect the chemical shifts of neither $\mathrm{NH}_{2}{ }^{+}$nor $\mathrm{CH}_{2}-\mathrm{NH}_{2}{ }^{+}$(Figure 8).

\section{Conclusion}

The suggested methods have the advantage of being simple, accurate, sensitive, and suitable for routine quality control of the drug in bulk form and in pharmaceutical formulations without any doubt of interference with excipients expected to present in formulations. The formation of RSG products was confirmed by IR and ${ }^{1} \mathrm{H}-\mathrm{NMR}$ techniques.

\section{References}

[1] A. Samii, J. G. Nutt, and B. R. Ransom, "Parkinson's disease," The Lancet, vol. 363, no. 9423, pp. 1783-1793, 2004.

[2] J. J. Chen, D. M. Swope, and K. Dashtipour, "Comprehensive review of rasagiline, a second-generation monoamine oxidase inhibitor, for the treatment of Parkinson's Disease," Clinical Therapeutics, vol. 29, no. 9, pp. 1825-1849, 2007.
[3] M. Fernandez, E. Barica, and S. Negro, "Development and validation of a reverse phase liquid chromatography method for the quantification of rasagiline mesylate in biodegradable PLGA microspheres," Journal of Pharmaceutical and Biomedical Analysis, vol. 49, pp. 1185-1191, 2009.

[4] R. N. Kumar, G. N. Rao, and P. Y. Naidu, "Stability indicating fast LC method for determination of ceftriaxone and tazobactam for injection related substances in bulk and pharmaceutical formulation," International Journal of Applied Biology and Pharmaceutical Technology, vol. 1, no. 1, pp. 145-157, 2010.

[5] X. Chen, X. Duan, J. Ma, P. Deng, H. Wang, and D. Zhong, "Validated LC-MS/MS method for quantitative determination of rasagiline in human plasma and its application to a pharmacokinetic study," Journal of Chromatogr B, vol. 873, pp. 203-208, 2008.

[6] M. Song, L. Wang, H. Zhao et al., "Rapid and sensitive liquid chromatography-tandem mass spectrometry: assay development, validation and application to a human pharmacokinetic study," Journal of Chromatography B, vol. 875, pp. 515-521, 2008.

[7] G. Devala Rao, S. Kathirvel, and S. V. Satyanarayana, "Simple spectrophotometric methods for the determination of rasagiline mesylate in pharmaceutical dosage form," Journal of Pharmacy Research, vol. 4, no. 1, pp. 61-62, 2011.

[8] B. Rama and K. Preeti, "UV Spectrophotometric method for the determination of rasagiline mesylate in bulk and pharmaceutical formulations," International Journal of Pharmaceutical Sciences Review and Research, vol. 5, no. 1, pp. 5-7, 2010.

[9] J. J. Thébault, M. Guillaume, and R. Levy, “Tolerability, safety, pharmacodynamics, and pharmacokinetics of rasagiline: a potent, selective, and irreversible monoamine oxidase type B inhibitor," Pharmacotherapy, vol. 24, no. 10, pp. 1295-1305, 2004.

[10] Z. Aydogmus, "Highly sensitive and selective spectrophotometric and spectrofluorimetric methods for the determination of ropinirole hydrochloride in tablets," Spectrochimica Acta Part A, vol. 70, no. 1, pp. 69-78, 2008.

[11] F. A. Siddiqui, M. S. Arayne, N. Sultana et al., "Spectrophotometric determination of gabapentin in pharmaceutical formulations using ninhydrin and $\pi$-acceptors," European Journal of Medicinal Chemistry, vol. 45, no. 7, pp. 2761-2767, 2010.

[12] K. Basavaiah, "Determination of some psychotropic phenothiazine drugs by charge-transfer complexation reaction with chloranilic acid," Farmaco, vol. 59, no. 4, pp. 315-321, 2004.

[13] N. S. Nahla, A. A. R. Sawsan, A. A. Shimaa, and E. K. Naglaa, "Spectrophotometric determination and thermodynamic studies of the charge transfer complexes of azelastine-HCl," Bulletin of Faculty of Pharmacy, Cairo University, vol. 49, no. 1, pp. 13-18, 2011.

[14] H. S. Bazzi, A. Mostafa, S. Y. AlQaradawi, and E.-M. Nour, "Synthesis and spectroscopic structural investigations of the charge-transfer complexes formed in the reaction of 2,6diaminopyridine with $\pi$-acceptors TCNE, chloranil, and DDQ," Journal of Molecular Structure, vol. 842, no. 1-3, pp. 1-5, 2007.

[15] E. Khaled, "Spectrophotometric determination of terfenadine in pharmaceutical preparations by charge-transfer reactions," Talanta, vol. 75, no. 5, pp. 1167-1174, 2008.

[16] P. Job, "Formation and stability of inorganic complexes in solution," Analytical Chemistry, vol. 9, pp. 113-203, 1928.

[17] ICH, In: international Conference on Harmonization of Technical Requirements for Registration of Pharmaceuticals for Human Use, Validation of Analytical Procedures: text and Methodology Q2 (R1), 2005. 
[18] A. Pawlukojć, G. Bator, L. Sobczyk, E. Grech, and J. NowickaScheibe, "Inelastic neutron scattering, Raman, infrared and DFT theoretical studies on chloranilic acid," Journal of Physical Organic Chemistry, vol. 16, no. 10, pp. 709-714, 2003.

[19] P. Larkin, Infrared and Raman Spectroscopy, Principles and Spectral Interpretation, Elsevier, Waltham, Mass, USA, 2011.

[20] T. Murata, Y. Morita, K. Fukui et al., "Phenalenyl-based highly conductive molecular systems with hydrogen-bonded networks: synthesis, physical properties, and crystal structures of 1,3- and 1,6-diazaphenalenes, and their protonated salts and charge-transfer complexes with TCNQ," Bulletin of the Chemical Society of Japan, vol. 79, no. 6, pp. 894-913, 2006.

[21] J. Sterling et al., Rasagiline formulations and processes for their preparation, United States Patent, US, 7598420B1, 2009.

[22] A. M. A. Adam, "Synthesis, spectroscopic, thermal and antimicrobial investigations of charge-transfer complexes formed from the drug procaine hydrochloride with quinol, picric acid and TCNQ," Journal of Molecular Structure, vol. 1030, pp. 26-39, 2012. 

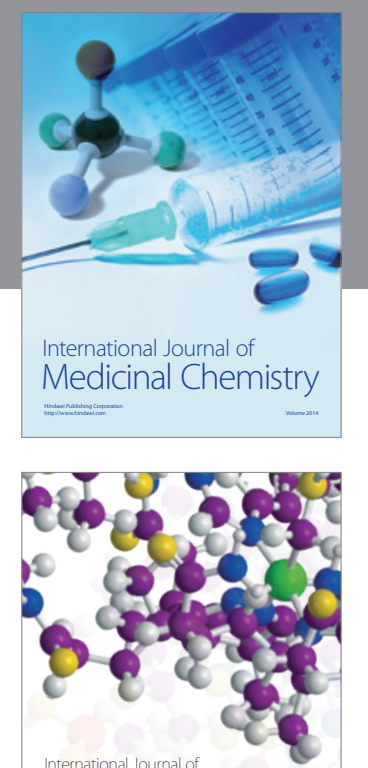

\section{Carbohydrate} Chemistry

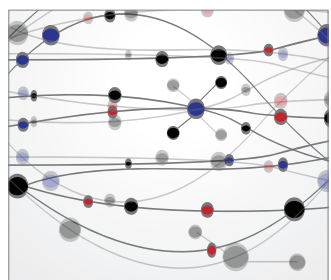

The Scientific World Journal
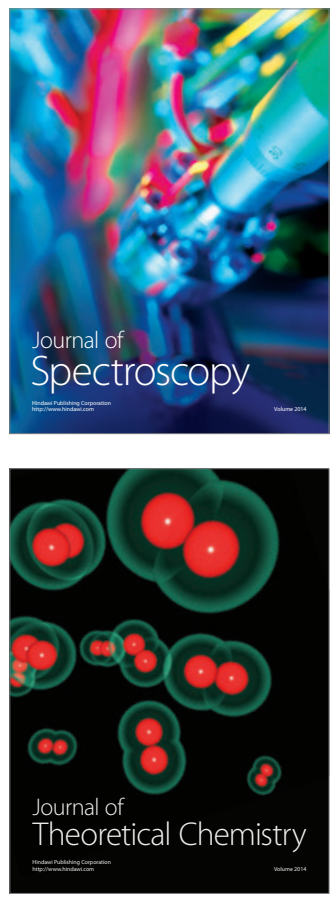
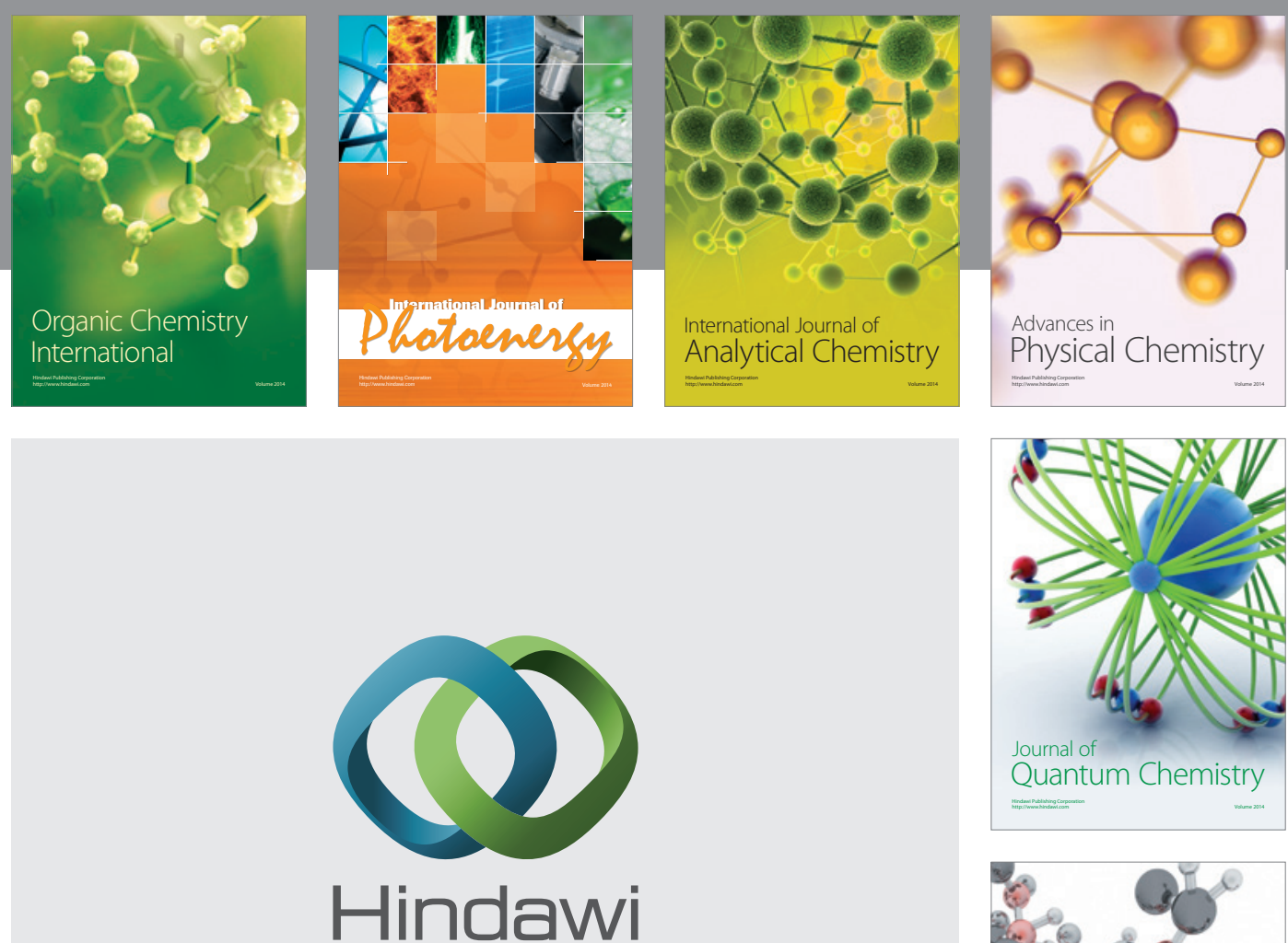

Submit your manuscripts at

http://www.hindawi.com

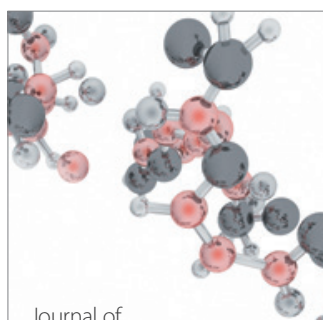

Analytical Methods

in Chemistry

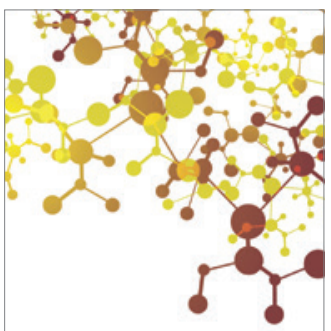

Journal of

Applied Chemistry

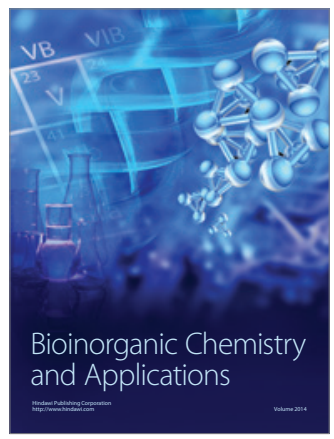

Inorganic Chemistry
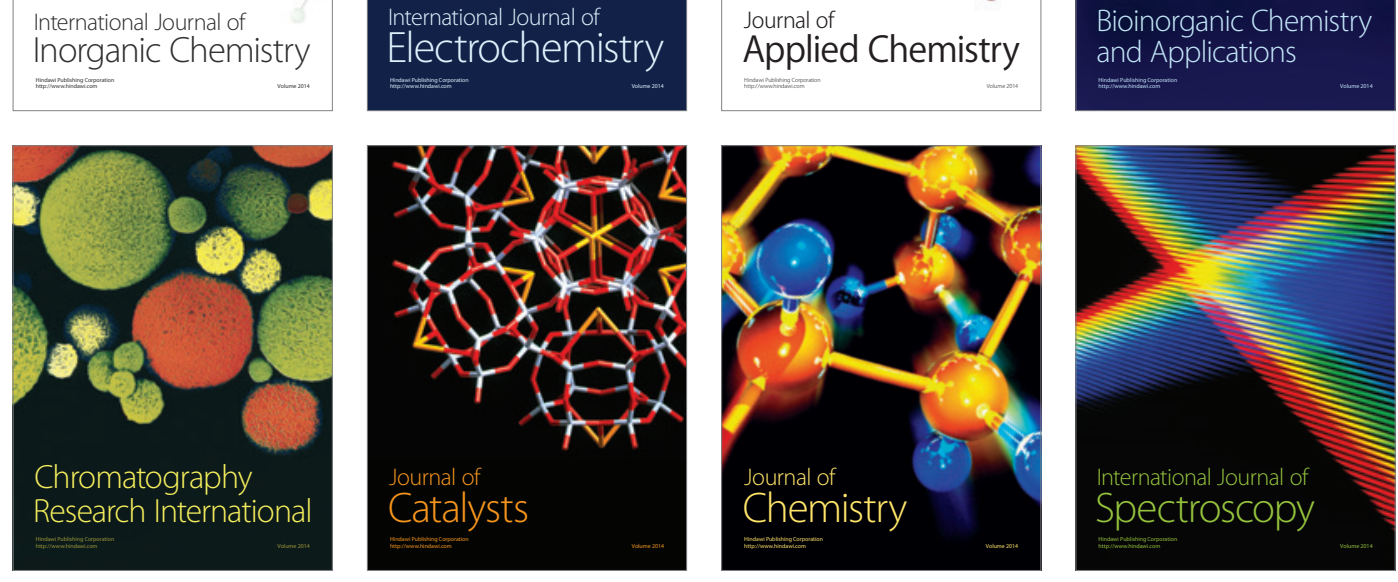